\title{
TRANSFER FUNCTION AND TIME SERIES OUTLIER ANALYSIS: MODELLING SOIL SALINITY IN LOAMY SAND SOIL BY INCLUDING THE INFLUENCES OF IRRIGATION MANAGEMENT AND SOIL TEMPERATURE ${ }^{\dagger}$
}

\author{
BASEM ALJOUMANI $^{1 *}$, JOSEP A. SÀNCHEZ-ESPIGARES ${ }^{2}$, NURIA CAÑAMERAS $^{3}$, GERD WESSOLEK $^{1}$ AND \\ RAMON JOSA ${ }^{3}$ \\ ${ }^{1}$ Department of Ecology, Soil Conservation, Technische Universität Berlin, Berlin, Germany \\ ${ }^{2}$ Department of Statistical and Operational Research, Universitat Politècnica de Catalunya (UPC), Barcelona, Catalunya, Spain \\ ${ }^{3}$ Department of Agri-food Engineering and Biotechnology, Universitat Politècnica de Catalunya (UPC), Barcelona, Catalunya, Spain
}

\begin{abstract}
In variable interval irrigation, simply including soil salinity data in the soil salinity model is not valid for making predictions, because changes in irrigation frequency must also be taken into account. This study on variable interval irrigation used capacitance soil sensors simultaneously to obtain hourly measurements of bulk electrical conductivity $\left(\sigma_{\mathrm{b}}\right)$, soil temperature $(t)$ and soil water content $(\theta)$. Observations of $\sigma_{\mathrm{b}}$ were converted so that the electrical conductivity of the pore water $\left(\sigma_{\mathrm{p}}\right)$ could be estimated as an indicator of soil salinity. Values of $\theta, t$ and $\sigma_{\mathrm{p}}$ were used to test a mathematical model for studying how $\sigma_{\mathrm{p}}$ cross-correlates with $t$ and $\theta$ to predict soil salinity at a given depth. These predictions were based on measurements of $\sigma_{\mathrm{p}}, t$, and $\theta$ at a shallow depth. As a result, prediction at shallow depth was successful after integrating intervention analysis and outlier detection into the seasonal autoregressive integrated moving average (ARIMA) model. We then used the (multiple-input/ one-output) transfer function models to logically predict soil salinity at the depths of interest. The model could also correctly determine the effect of the irrigation event on soil salinity. Copyright @ 2017 John Wiley \& Sons, Ltd.
\end{abstract}

KEY WORDS: capacitance device; pore water electrical conductivity; autoregressive integrated moving average (ARIMA) model; outlier detection; transfer function model

Received 9 July 2016; Revised 27 September 2017; Accepted 27 September 2017

\section{RÉSUMÉ}

Dans le cas d'une irrigation à intervalle variable, il ne suffit pas d'inclure des données de salinité dans un modèle prédictif, car la fréquence des irrigations influe sur la salinité. Nous avons utilisé des capteurs capacitifs pour mesurer au pas de temps horaire la conductivité électrique apparente $\left(\sigma_{\mathrm{b}}\right)$, la température du sol $(t)$ et la teneur en eau du sol $(\theta)$. Les observations $\sigma$ de conductivité électrique ont été converties de façon à ce que la teneur en eau dans les pores $\left(\sigma_{\mathrm{p}}\right)$ puissent être estimées comme indicateur de la salinité. Les valeurs de $\theta, t$ et $\sigma_{\mathrm{p}}$ ont été utilisés pour tester un modèle mathématique pour étudier comment $\sigma_{\mathrm{p}}$ s'auto corrèle avec $t$ et $\theta$ pour prédire la salinité du sol à une profondeur donnée. Ces prédictions sont basées sur des mesures de $\sigma_{\mathrm{p}}, t$ et $\theta$ à faible profondeur. En conséquence, la prédiction à faible profondeur a réussi après une analyse intégrante et la détection des valeurs aberrantes dans un modèle de moyenne mobile saisonnière autorégressive intégrée (ARIMA). Nous avons ensuite utilisé des modèles de fonction de transfert (plusieurs entrées, une seule sortie) pour prédire la salinité du sol aux profondeurs d'intérêt. Le modèle a pu également déterminer correctement l'effet de l'évènement d'irrigation sur la salinité du sol. Copyright @ 2017 John Wiley \& Sons, Ltd.

MOTS CLÉS: dispositif de mesure de capacitance; eau de conductivité électrique porale; modèle intégré autorégressif de moyenne mobile (ARIMA); détection des valeurs aberrantes; modèle de fonction de transfert

\footnotetext{
*Correspondence to: Dr Basem Aljoumani, Department of Ecology, Soil Conservation, Technische Universität Berlin, Ernst-Reuter-Platz 1, 10587 Berlin, Germany. E-mail: basem.aljoumani@tu-berlin.de

†Analyse des fonctions de transfert et de séries chronologiques aberrantes: modélisation de la salinité d’un sol limono-sableux sous différentes conditions de température et de gestion de l'irrigation.
}

Contract/grant sponsor: Parc Agrari Del Baix Llobregat (Barcelona); contract/grant number:

Contract/grant sponsor: Alexander von Humboldt-Stiftung; contract/grant number: 


\section{INTRODUCTION}

Salinity is shown to have a large impact on plants by reducing their ability to take up water. This creates an imbalance of plant nutrients, which ultimately leads to the degradation of land. Munns (2002) demonstrated that when salts accumulate excessively in older leaves, premature senescence occurs, causing a reduction in the leaf area available for photosynthesis and thus rendering the plant less able to sustain growth.

Determining the electrical conductivity of soil pore water $\left(\sigma_{\mathrm{p}}\right)$ conventionally requires extraction of the water from the soil by suction or measurement of saturated paste conductivity, both of which are labour-intensive methods. Also, there is always uncertainty as to whether all ions have been collected in the extract sample (Hilhorst, 2000).

A more recent method for temporally and spatially evaluating the $\sigma_{\mathrm{p}}$ is to convert the bulk electrical conductivity $\left(\sigma_{\mathrm{b}}\right)$ to $\sigma_{\mathrm{p}}$ by using methods, models and estimates such as those described by Rhoades et al. (1990) or Mualem and Friedman (1991).

\section{SOIL SALINITY MEASUREMENT}

New sensors have been developed to measure $\sigma_{\mathrm{b}}$, such as time-domain reflectometry (TDR) and frequency-domain reflectometry (FDR).

Temperature and water content significantly affect the accuracy of determining $\sigma_{\mathrm{p}}$. Therefore, a precise real-time measurement of $\sigma_{\mathrm{p}}$ depends on electrical conductivity sensors being able to simultaneously measure three variables: water content $(\theta)$, soil temperature $(t)$ and $\sigma_{\mathrm{b}}$.

The $\sigma_{\mathrm{b}}$ of the soil system is determined by estimating the conductance pathways in the system, namely: (i) solidliquid interphase; (ii) solid phase; (iii) liquid phase. In agricultural practice, it is beneficial to recognize the level of electrical conductivity of the liquid phase $\left(\sigma_{\mathrm{p}}\right)$ that is contained in the soil pores, as it provides a sound indicator of the solute concentration contained within the soil. A strong linear correlation between the values of the dielectric soil constant $\left(\varepsilon_{\mathrm{b}}\right)$ and $\sigma_{\mathrm{b}}$ in most soil types was discovered by Malicki et al. (1994). This discovery was further developed by Hilhorst (2000), whereby a successful conversion of $\sigma_{\mathrm{b}}$ to $\sigma_{\mathrm{p}}$ was made possible by applying a theoretical model that outlined the linear relationship between $\sigma_{\mathrm{b}}$ and $\varepsilon_{\mathrm{b}}$.

$\sigma_{\mathrm{p}}$ was estimated by Hilhorst (2000) using the equation

$$
\sigma_{\mathrm{p}}=\frac{\varepsilon_{\mathrm{p}} \sigma_{\mathrm{b}}}{\varepsilon_{\mathrm{b}}-\varepsilon_{\sigma_{\mathrm{b}}=0}}
$$

where $\sigma_{\mathrm{p}}$ is the pore water electrical conductivity $\left(\mathrm{dS} \mathrm{m} \mathrm{m}^{-1}\right)$; $\varepsilon_{\mathrm{p}}$ is the real portion of the soil pore water's dielectric permittivity (unitless); $\sigma_{\mathrm{b}}$ represents the bulk electrical conductivity ( $\left.\mathrm{dS} \mathrm{m}^{-1}\right) ; \varepsilon_{\mathrm{b}}$ is the real portion of the bulk soil's dielectric permittivity (unitless); $\varepsilon_{\sigma \mathrm{b}=0}$ is the real portion of the soil's dielectric permittivity when the bulk electrical conductivity has a value of 0 (unitless). It should be noted that $\varepsilon_{\sigma \mathrm{b}=0}$ is an offset of the linear relationship between $\varepsilon_{\mathrm{b}}$ and $\sigma_{\mathrm{b}}$. In the soils used for Hilhorst's study (2000), $\varepsilon_{\sigma \mathrm{b}=0}$ depended on the soil type and it varied between 1.9 and 7.6. So, he recommended 4.1 as a generic offset.

Having simultaneous data on $\sigma_{\mathrm{p}}, t$ and $\theta$ enabled us to properly build models that could precisely predict soil salinity by taking into account the changes in $\theta$ and $t$.

\section{Soil salinity movement models}

In predicting solute transport between the land surface and groundwater table, deterministic convection-dispersion equations based on Fickian diffusion are convenient tools for describing solute movement, as they allow a limited number of field studies to be extracted to various soils, crops and climates, as well as to differing tillage and water management regimes (Genuchten Van, 1991).

However, questions have been raised in the literature as to the utility of these equations when describing solute transport in structured soils where there exist large continuous voids, for example: natural inter-aggregate pores, inter-pedal voids, earthworm tunnels and gopher holes. The movements of solutes in these voids can be very different from those that occur through materials that are fairly homogeneous (Beven and Germann, 1982; White, 1985). Because most soils are heterogeneous, specific methods are required for simulating heterogeneous fieldscale transport processes (Genuchten Van, 1991).

As a way of managing the heterogeneous nature of soil and predicting the evolution of soil solutes, some experimenters prefer to adopt stochastic models instead of using constant values to describe the possible future evolution of soil solutes. These models assume that solute transport has random variables, and each variable is assigned a discrete value in accordance with a specified probability distribution.

The use of stochastic models has increased significantly over the last decade. For example, they have been employed in: artificial neural networks (ANNs) (Huang et al., 2010); agronomic applications that model crop development (Zhang et al., 2009; Fortin et al., 2010); and predicting crop yields (Park et al., 2005; Green et al., 2007; Khazaei et al., 2008). Zou et al. (2010) collected silt loam soil profile data on a monthly basis from 2001 to 2006 and used them to compare the back-propagation neural network (BPNN) model and the autoregressive integrated moving average (ARIMA) model. Their objective was to predict (i) the average moisture content in the top 1-m profile by using the moisture content measured at $0.60 \mathrm{~m}$ depth, and (ii) the average salt content measured at various depths of the 
soil profile $(0.10,0.20$ and $0.45 \mathrm{~m})$. Mishra and Desai (2005) used ARIMA and seasonal ARIMA models to forecast droughts. Sarangi et al. (2006) used ANNs to model root zone soil salinity and the salinity of subsurface drainage effluent in the coastal clay soils of rice fields in Andhra Pradesh, India. They found that drainage effluent salinity could be predicted better by feeding the input values to the ANNs after a time lag rather than by using the conceptual SALTMOD model.

In irrigated agriculture, the ARIMA model has the potential to predict soil salinity, in that it uses past observations as a means of predicting future patterns. Previous models assumed a fixed spacing between irrigation events and that therefore the ARIMA model could be applied suitably. One example could be that of a farmer who irrigates a field every 10 days with the expectation that the field data set will provide an ARIMA model in which there is a decrease in soil salinity on the tenth day. This is known as a post-irrigation event. However, if the farmer decides to apply variable interval irrigation and thus uses a spacing of 9 days between irrigation events, the ARIMA models will not be capable of effective predictions in this case. In this instance, the previously identified ARIMA model would show a decrease in soil salinity after 10 days instead of after 9. Wei (1989) states that - in order to successfully apply an ARIMA model to time series data sets with outliers-it is necessary to incorporate intervention analysis models and outlier detection.

Aljoumani et al. (2012) explained why the ARIMA models cannot predict soil water content in cases of variable interval irrigation. By including intervention analysis and outlier detection in the ARIMA model, they were able to predict the water content of the soil.

\section{Outliers versus intervention variables}

When considering the time series of soil salinity, soil moisture and soil temperature, a key distinction is made between outliers and intervention variables. If a situation arises where a priori information relating to a special event (in this case, an irrigation event) proves to cause possible abnormal observations, the effect of this event should be captured through intervention analysis. In this study, the abnormal observations of the soil salinity caused by irrigation events are captured through intervention analysis.

Conversely, if anomalies in the observations are represented without a priori information on their occurrence or on the dynamic patterns of their effects (i.e. a precipitation event), this represents an outlier. To predict soil salinity, we incorporated variable interval irrigation into the ARIMA model as a means of examining the effectiveness of the irrigation event by capturing, with intervention analysis, the abnormal observations of soil salinity time series caused by irrigation events. For this to be possible, it was necessary to perform two procedures. First, we detected and removed the outliers, which therefore caused an upward trend in soil salinity forecasts due to an absence of effect from the irrigation events (outliers). Second, we assessed the intervention effects of the irrigation event and included them in the model, which thus resulted in a decrease of soil salinity at the time of irrigation. In this second procedure, the weight of the irrigation coefficient determined the extent of the decrease. This complementary analysis provides an advantage that can be attributed to the likelihood of having a well-realized irrigation schedule (which is based on a short duration of 1 day or even $1 \mathrm{~h}$ ) combined with the knowledge of its effect on the soil salinity. Therefore, the next irrigation event will be determined at the point where the prediction for soil salinity exceeds the plant's tolerance to salts. For example, to predict $\sigma_{\mathrm{p}}$ in a lettuce field, we determine the time of irrigation when the predicted value of $\sigma_{\mathrm{p}}$ exceeds 2 $\mathrm{dS} \mathrm{m} \mathrm{m}^{-1}$, even though the soil moisture value is at field capacity. This is because lettuce crops are sensitive to salinity.

Aljoumani et al. (2014) showed that it is important to capture the effect of irrigation events on bulk electrical conductivity and to then use the effect as an outlier for improving the fitted model. For the same reasons explained in those references, intervention analysis and outlier detection should complement the ARIMA model when modelling soil salinity in variable interval irrigation.

For the purpose of describing soil salinity fluctuations, incorporating the time series outlier and intervention analysis into the ARIMA model provides two advantages. First, if we employ intervention analysis results in the input series that is represented by a simple pulse or step indicator function, this will indicate whether or not an irrigation event is in fact present. This further improves the efficiency of irrigation scheduling and its effect on soil salinity by including the irrigation event's effectiveness in the ARIMA model. Outlier correction is employed primarily to modify the data in a way that accepts the normality hypothesis of the ARIMA model (Box et al., 1994).

The second advantage results from including the outlier analysis in the ARIMA model. This provides more precision from reducing the residual variance of the model.

Many studies have confirmed the effects of soil moisture and temperature when estimating soil salinity. However, McKenzie et al. (1989) and Slavich and Peterson (1990) found that soil texture, $\theta$ and $t$ all affect the calibration measurements of electromagnetic (EM) induction when predicting $\sigma_{\mathrm{b}}$. Sarangi et al. (2006) found that soil salinity correlates both with the content of soil water and with temperature. However, we found no studies that developed models for predicting soil salinity by taking into account future changes in soil water content and soil temperature. 
This study seeks to fulfil the general objective of modelling soil salinity for predictive purposes while also considering future variations in soil water and soil temperature. The specific objectives of this study are as follows:

- to study the autocorrelation as well as the partial correlation functions of the estimated $\sigma_{\mathrm{p}}, \theta$ and $t$, specifically when they are measured at shallow depths; the crosscorrelation function between $\theta, \sigma_{\mathrm{p}}$, and $t$ at $0.10 \mathrm{~m}$ depth; the estimated $\sigma_{\mathrm{p}}$ at an interested depth $(0.10 \mathrm{~m})$; and the average soil salinity in the top $0.60 \mathrm{~m}$ of the soil profile;

- to develop models for predicting the soil salinity at various greater depths by measuring $\sigma_{\mathrm{p}}, \theta$ and $t$ at a single shallow depth;

- to employ outlier analysis and intervention analysis in examining how irrigation events affect soil salinity.

\section{MATERIALS AND METHODS}

Hourly field observations of bulk electrical conductivity $\left(\sigma_{b}\right)$, soil temperature $(t)$, and soil water content $(\theta)$

Commencing on 23 April 2010, the observations were carried out over a period of 55 days in the Agricultural Park of Baix Llobregat, which is situated $5 \mathrm{~km}$ south of Barcelona, Spain. The set-up comprised an experimental field area on $275 \mathrm{~m}^{2}(55 \times 5 \mathrm{~m})$ of land with planted lettuce (Lactuca sativa) which was irrigated by means of a furrow system. Four irrigation events were applied, with each irrigation dose set at $26 \mathrm{~mm}$ applied over a period of 20-26 min. The site's soil was fairly uniform, silty loam, and the bulk density ranged between 1.4 and $1.5 \mathrm{~g} \mathrm{~cm}^{-3}$ as far down as $0.75 \mathrm{~m}$ of depth. The water table lay $4 \mathrm{~m}$ below the surface of the soil. We measured the distributions of $\sigma_{\mathrm{b}}, t$ and $\theta$ across the soil profile in the test furrow by using capacitance soil moisture sensors (5TE, Decagon Devices, Inc., Pullman, Wash.), which were installed at depths of $0.10,0.20$, $0.35,0.50$ and $0.60 \mathrm{~m}$ below the surface of the soil. Then, in order to convert $\sigma_{\mathrm{b}}$ to $\sigma_{\mathrm{p}}$, we used the Hilhorst model (2000). To define the models for predicting $\sigma_{\mathrm{p}}$, we used: a total of 1318 observations of estimated $\sigma_{\mathrm{p}}$; measurements of $t$ and $\theta$ at a depth of $0.10 \mathrm{~m}$; and the $\sigma_{\mathrm{p}}$ averages for the upper $0.60 \mathrm{~m}$. These were then validated by using an additional 659 observations. All the details about field observations and the data plot are described in Aljoumani et al. (2012, 2014).

\section{Model identification and forecast}

The time series analysis of $\sigma_{\mathrm{p}}, t$ and $\theta$ was carried out in three steps. The first involved applying the Box-Jenkins method (Box et al., 1994) in order to identify an appropriate univariate model for the time series of $\sigma_{\mathrm{p}}, t$ and $\theta$ at $0.10 \mathrm{~m}$ depth. This was done using the seasonal ARIMA model:

$$
(p, d, q) \times(P, D, Q)_{S}
$$

where $p$ and $q$ are the regular autoregressive and moving average orders; $P$ and $Q$ are the seasonal autoregressive and moving average factors; $d$ and $D$ are the orders of differencing for the regular and seasonal part; and, finally, subindex $S$ represents the seasonal period, which in this study is $24 \mathrm{~h}$.

In the second step, we included irrigation duration in the model as an intervention analysis in order to evaluate its effects. Then, we conducted a search to establish whether or not the univariate series contains any outliers. In the third step, we modelled the linear system in order to identify the appropriate transfer function. This was done by using, as input, the time series of $t$ and $\theta$ at a depth of $0.10 \mathrm{~m}$, with the outputs being the time series of $\sigma_{\mathrm{p}}$ at a depth of $0.10 \mathrm{~m}$ and the average $\sigma_{\mathrm{p}}$ calculated for the top $0.60 \mathrm{~m}$ of soil.

Univariate time series analysis. For elucidating the patterns of the $\sigma_{\mathrm{p}}, t$ and $\theta$ data at $0.10 \mathrm{~m}$ depth, and for finding the average $\sigma_{\mathrm{p}}$ in the top $0.60 \mathrm{~m}$ depth of soil, we implemented univariate seasonal (ARIMA) $(p, d, q) \times(P, D, Q)_{S}$ modelling techniques. Moreover, for the purpose of identifying and fitting the ARIMA models, four phase approaches were adopted, namely: model identification, model parameter estimation, diagnostic checking, and forecasting. As part of the autoregressive (AR) process, each value of a time series was dependent on the preceding value, in addition to a random shock. The AR model for a centred time series with order $p$ can be defined as

$$
X_{t}=\varphi_{1} X_{t-1}+\varphi_{2} X_{t-2}+\ldots+\varphi_{p} X_{t-p}+a_{t}
$$

or

$$
\left(1-\varphi_{1} B-\varphi_{2} B^{2}-\ldots-\varphi_{p} B^{p}\right) X_{t}=a_{t}
$$

where $\varphi_{j}$ denotes the $j$ th $\mathrm{AR}$ parameter, $a_{t}$ the Gaussian white-noise error, and $B$ the backshift operator in which $B^{p} X_{t}=X_{t}-p$. The errors for the moving average (MA) model are the average of the random errors for this period and previously. We define the MA time series of order $q$ by means of

$$
X_{t}=a_{t}+\theta_{1} a_{t-1}+\theta_{2} a_{t-2}+. .+\theta_{q} a_{t-q}
$$

or

$$
X_{t}=\left(1+\theta_{1} B+\theta_{2} B^{2}+. .+\theta_{q} B^{q}\right) a_{t}
$$

where $\theta_{q}$ is the $q$ th MA parameter.

Identifying AR and MA models requires a stationary time series. Although this implies that the variance and mean 
values are constant, some transformation is needed in order to identify the model.

Successive differences of the data's regular and seasonal components were taken to ensure no trend in mean. The required numbers of differences for the stationary time series were denoted by $d$ and $D$. Moreover, in applying the logarithmic transformation that is usually used, no trend in variance is obtained (Soebiyanto et al., 2010; Quinn, 1985; Vandaele, 1983).

In any time series, $X_{t}$, the $\operatorname{ARIMA}(p, d, q) \times(P, D, Q)_{S}$ of $X_{t}$ is

$$
\begin{aligned}
& \varphi_{\mathrm{p}}(B) \Phi_{P}\left(B^{S}\right)(1-B)^{d}\left(1-B^{S}\right)^{D} X_{t} \\
& \quad=\theta_{q}(B) \Theta_{Q}\left(B^{S}\right) a_{t}
\end{aligned}
$$

where $\varphi_{p}(B)$ and $\theta_{q}(B)$ are the regular autoregressive and moving average factors, and $\Phi_{P}\left(B^{S}\right)$ and $\Theta_{Q}\left(B^{S}\right)$ are the seasonal autoregressive and moving average factors.

The autocorrelation function (ACF) and the partial autocorrelation function (PACF) were used to identify time series models (McCleary and Hay, 1980; Pankratz, 1983; Hoff, 1983). ACF measures the relation between $X_{t}$ and $X_{t+K}$, where $K$ is the time lag. We used PACF in order to take into account any dependence on intermediate elements (i.e. those inside the lag) (Box et al., 1994; McDowall et al., 1980; Wei, 1989).

The maximum likelihood method was chosen for this study in order to estimate the model parameters. In addition, by constructing the Wald test statistic, we were able to determine the significance of these parameters.

Diagnostic checking tests were used to ascertain whether the residuals showed any autocorrelation at any lags. The assumptions would be satisfied if the ACF and PACF of the residuals were non-significant at all lags.

Intervention analysis and outlier detection. Outliers in the $\sigma_{\mathrm{p}}, t$ and $\theta$ data refer to soil at $0.10 \mathrm{~m}$ depth and to the average $\sigma_{\mathrm{p}}$ in the top $0.60 \mathrm{~m}$. They were removed using Grubbs' test for detecting outliers (Grubbs, 1969):

$$
Z=\frac{|M-V|}{\mathrm{SD}}
$$

where $Z$ is the test statistic, $M$ the mean of the values, $V$ the value being tested, and SD the standard deviation of the values. A total of 1318 observations of $\sigma_{\mathrm{p}}, t$ and $\theta$ were available. Assuming an outlier probability of $5 \%$, we set the outlier test statistic at 4 (Grubbs, 1969). The values of $\sigma_{\mathrm{p}}, t$ and $\theta$ that yielded test statistics greater than or equal to 4 were eliminated from the data set. In order to properly assess how precipitation and other observed irregularities impacted the time series of $\sigma_{\mathrm{p}}, t$ and $\theta$, two types of outliers were considered: additive outliers (AO) and temporary changes (TC). At the same time, level shift (LS) was used as an intervention analysis to assess the impact of the irrigation event on the time series of $\sigma_{\mathrm{p}}, t$ and $\theta$. AO is a pulse that affects the time series at one period only. TC is an event that decays exponentially, according to a prespecified dampening factor. LS is an event that permanently affects the subsequent level of a series (Chen and Liu, 1993).

Let $Z_{t}$ denote the underlying time series process, which is free of the impact of outliers and occurs prior to the irrigation event; and let $X_{t}$ denote the observed time series. We assume that $Z_{t}$ follows the seasonal $\operatorname{ARIMA}(p, d, q)(P, D, Q)$ ${ }_{S}$ model $\varphi_{p}(B) \Phi_{P}\left(B^{s}\right)(1-B)^{d}\left(1-B^{s}\right)^{D} Z_{t}=\theta_{q}(B) \Theta_{Q}\left(B^{s}\right) a_{t}$. Based on these assumptions, the appropriate model for assessing the impact of the control is

$$
\begin{aligned}
X_{t}= & \sum_{r=1}^{n_{r}} \omega_{r} S_{T_{r}}^{(\mathrm{LS})}+\sum_{i=1}^{n_{i}} \omega_{i} P_{T_{i}}^{(\mathrm{TC})}+\sum_{j=1}^{n_{j}} \omega_{j} P_{T_{j}}^{(\mathrm{AO})}+Z_{t} \\
= & \sum_{r=1}^{n_{r}} \omega_{r} S_{T_{r}}^{(\mathrm{LS})}+\sum_{i=1}^{n_{i}} \omega_{i} P_{T_{i}}^{(\mathrm{TC})}+\sum_{j=1}^{n_{j}} \omega_{j} P_{T_{j}}^{(\mathrm{AO})} \\
& +\frac{\theta_{q}(B) \Theta_{Q}\left(B^{S}\right)}{\varphi_{p}(B) \Phi_{p}\left(B^{S}\right)(1-B)^{d}(1-B)^{D}} a_{t}
\end{aligned}
$$

where $\omega_{r}$ is permanent change in the mean level following the intervention (i.e. the irrigation event), and $S_{T_{r}}^{(L S)}$ is a step indicator at the time of irrigation $T_{r}$, where

$$
S_{T_{r}}^{(L S)}\left\{\begin{array}{cc}
0 & t<T_{r} \\
1 & t \geq T_{r}
\end{array}\right.
$$

In this study, the level shift (LS) in the soil salinity time series is produced by the irrigation events; and, since the date of these events is known a priori, we were able to assess how irrigation events affect soil salinity by completing the ARIMA model with intervention analysis.

is the transitory change in the mean level following any unusual observations (e.g. precipitation); $P_{T_{i}}^{(T C)}$ and $P_{T_{j}}^{(A O)}$ are pulse indicators taken at unusual observation times $T_{i} \operatorname{and} T_{j}$, respectively, where

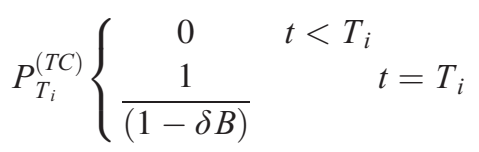

and

$$
P_{T_{j}}^{(A O)}\left\{\begin{array}{cc}
0 & t \neq T_{j} \\
1 & t=T_{j}
\end{array}\right.
$$

$\delta$ is a dampening factor with the default value of 0.7 (Chen and Liu, 1993).

The exploratory method of visualizing the outliers in time series analyses has been well established in other fields, and this seasonal trend decomposition (commonly known as 
'STL') uses locally weighted regression (loess) (Cleveland et al., 1990; Hafen et al., 2009). The STL method is straightforward and flexible for specifying the amount of variation in the seasonal components and trends of time series; furthermore, it provides robust estimates without any distortions resulting from transient outliers (Cleveland et al., 1990). STL was utilized to model the $24 \mathrm{~h}$ prevalent soil salinity, soil water and soil temperature time series. STL is a filtering procedure for decomposing a time series into additive components of variation (trend, seasonality and the remainder); and it does so by applying loess smoothing models (Cleveland et al., 1990; Chaloupka, 2001).

Transfer function approach. We can use the observations and predictions from two-time series (input $X_{1 t}$ and $X_{2 t}$ ) to estimate the outcome of another time series (output $G_{t}$ ). This is done by a relatively small number of parameters to model the linear system, which takes the form

$$
G_{t}=\frac{A_{1}(B)}{C_{1}(B)} X_{1, t-b_{1}}+\frac{A_{2}(B)}{C_{2}(B)} X_{2, t-b 2}+a_{t}
$$

where $A(B)$ and $C(B)$ are, respectively, the polynomials of the $s$ and $r$ orders:

$$
\begin{aligned}
& A(B)=\left(A_{0}-A_{1} B-A_{2} B^{2}-\ldots-A_{s} B^{s}\right) \\
& C(B)=\left(1-C_{1} B-C_{2} B^{2}-\ldots-C_{r} B^{r}\right)
\end{aligned}
$$

where $A_{0}, A_{1}, A_{2}, \ldots, A_{s}$ and $C_{1}, C_{2}, \ldots, C_{r}$ are the parameters of the model, $b$ is the latent parameter, $B$ is the backshift operator, and $a_{t}$ is a disturbance (noise).

$A(B) / C(B)$ is the system's designated transfer function. In modelling a transfer function, the procedure involves three steps: (i) identification, (ii) estimation and (iii) checking the model. The same filter can be applied to the output series $G_{t}$ (pre-whitening) by employing a univariate model for the inputs of $X_{1 t}$ and $X_{2 t}$ while using white noise residuals. Cross-correlating the two residuals identifies the transfer function form.

The transfer function in this study uses the soil water $(\theta)$ and soil temperature $(t)$ that were observed at $0.10 \mathrm{~m}$ depth for the primary series $\left(X_{1 t}\right.$ and $\left.X_{2 t}\right)$. We chose the output series $\left(G_{t}\right)$ from the time series of soil salinity $\left(\sigma_{\mathrm{p}}\right)$ that were observed at a depth of $0.10 \mathrm{~m}$, as well as the average soil salinity $\left(\sigma_{\mathrm{p}}\right)$ from the upper $0.60 \mathrm{~m}$ of the soil profile. The formula used by Wu et al. (1997) was adopted for calculating the average soil salinity $\left(\sigma_{\mathrm{p}}\right)$ in the upper $0.60 \mathrm{~m}$ of the soil profile.

The software R, version 2.15.1 (R Development Core Team, 2012), executed all model identifications and subsequently predicted soil salinity at various depths (Cryer and Chan, 2008; Shumway and Stoffer, 2006).

\section{RESULTS AND DISCUSSION}

Figure 1 shows the variation of $\theta, t$, and $\sigma_{\mathrm{p}}$ at $0.10 \mathrm{~m}$ depth over time. Decreases in $\sigma_{\mathrm{p}}$ signalled the significant effects of irrigation events that occurred almost on days 4, 27, 32

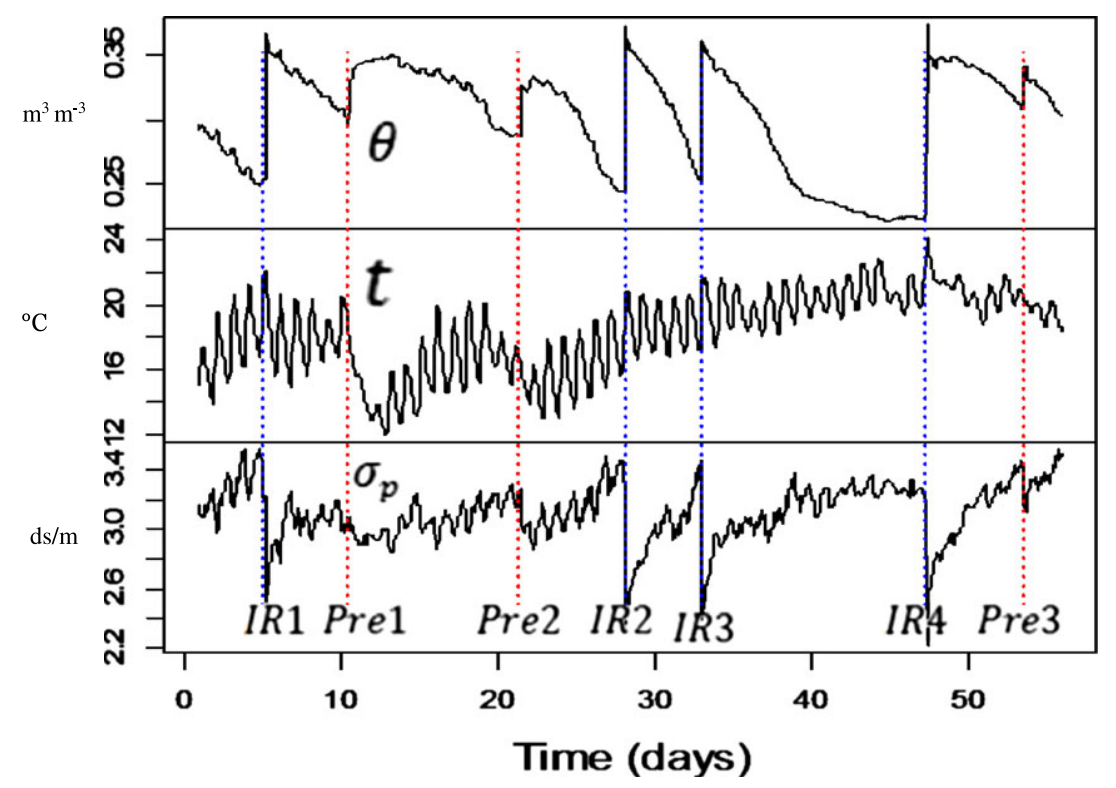

Figure 1. Variation of soil water content $\left(\theta, \mathrm{m}^{3} \mathrm{~m}^{-3}\right)$, soil temperature $\left(t,{ }^{\circ} \mathrm{C}\right)$ and soil salinity $\left(\sigma_{\mathrm{p}}, \mathrm{dS} \mathrm{m} \mathrm{m}^{-1}\right)$ at $0.10 \mathrm{~m}$ depth with time. IR1, IR2, IR3 and IR4 are the irrigation events applied on days 4.29, 27.20, 32.04 and 46.33. Pre1, Pre2, and Pre3 are the precipitation events on days 9.33, 20.50 and 52.54. [Colour figure can be viewed at wileyonlinelibrary.com] 
and 46, as well as from precipitation events almost on days 9, 21 and 53. Figure 1 also shows that $t$ increased after irrigation, due to the irrigation water being warmer than the soil before irrigation.

The opposite occurred with precipitation: Figure 1 shows that $t$ decreased after precipitation; acknowledgement of these fluctuations will help in modelling $\sigma_{\mathrm{p}}$ as a function of $\theta$ and $t$, as explained below. Later, we developed the ARIMA model for $\sigma_{\mathrm{p}}$ time series at $0.10 \mathrm{~m}$ depth and completed it by including the irrigation event as an intervention and the precipitation as outlier detection.

Univariate time series modelling of soil salinity at $0.10 \mathrm{~m}$ depth

We can see that the time series is non-stationary, as indicated by the significant slow convergence of ACF in the original $\sigma_{\mathrm{p}}$ time series at $0.10 \mathrm{~m}$ depth (Figure 2A). As a means for obtaining a stationary time series, we differentiated the original series (first-order difference and seasonal first-order difference). There is no requirement for applying a logarithmic transformation in this case, as there is no trend in variance observed in the series.

The ACF and PACF of the differentiated time series found that the regular component of the series was approximately AR (3) and that the seasonal component was MA (1). This is because the ACF (Figure 2B) found significant correlations only at the first three lags of PACF and the 24th lag of ACF.

The ARIMA $(p, d, q)(P, D, Q)_{S}$ model of the $\sigma_{\mathrm{p}}$ time series at a depth of $0.10 \mathrm{~m}$ resulted in ARIMA $(3,1,0)(0,1$, $1)_{24}$. The model is expressed with the usual notation by

$$
\begin{aligned}
& \left(1-\varphi_{1} B-\varphi_{2} B^{2}-\varphi_{3} B^{3}\right)(1-B)\left(1-B^{24}\right) X_{t} \\
& \quad=\left(1+\theta_{24} B^{24}\right) a_{t}
\end{aligned}
$$

where $a_{t}$ is a white noise term that is independent and identically distributed with zero mean, and the variance $=2.8 \times$ $10^{-7} ; \varphi_{1}=0.2088, \varphi_{2}=-0.0468 . \varphi_{3}=-0.0883$ are AR parameters. The $\theta_{24} \Theta 24=0.99$ parameter of the seasonal MA part indicates that the model is almost non-invertible. Therefore, it is inadequate and needs to be improved in structure.
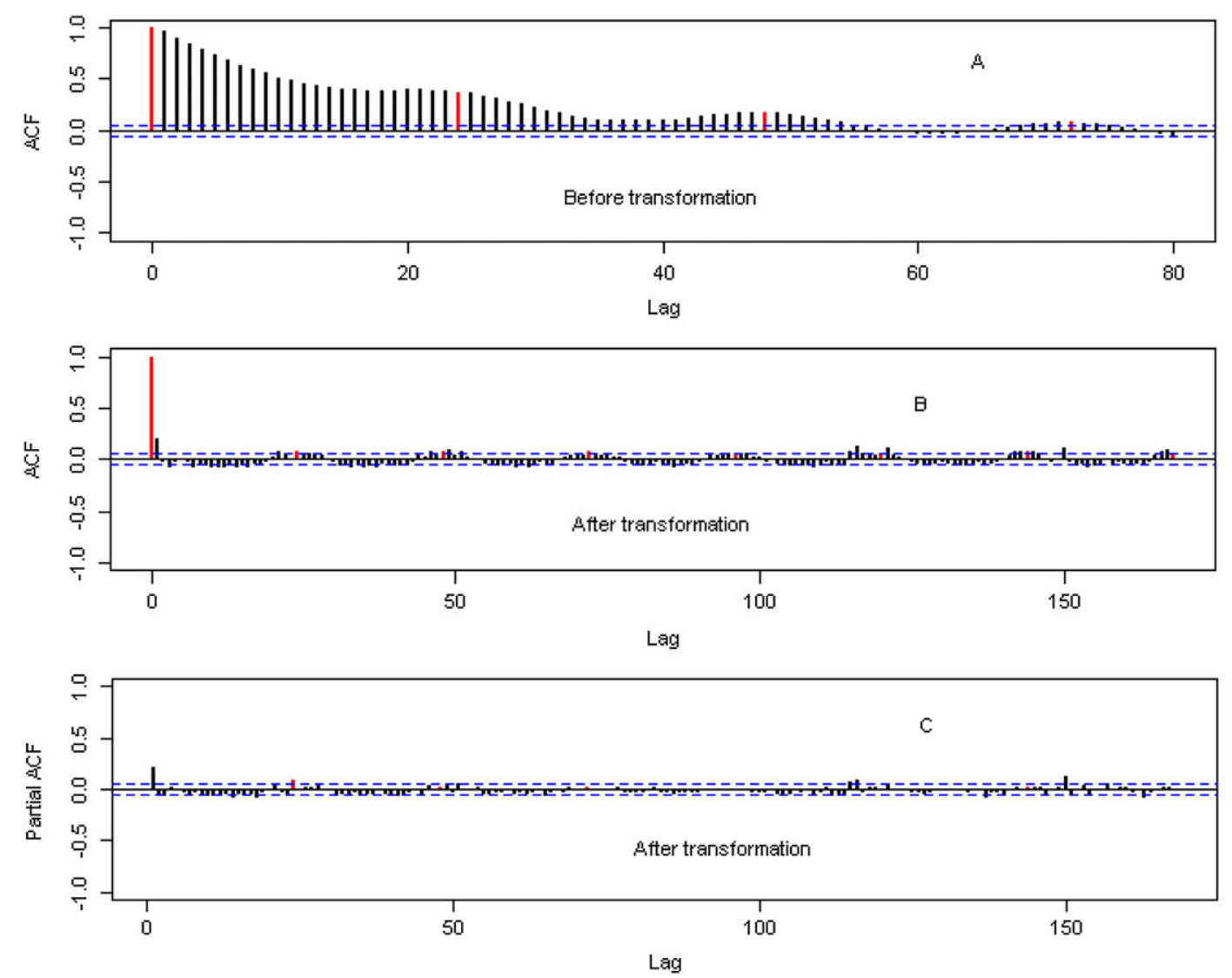

Figure 2. (A) Autocorrelation function (ACF) of the original data, (B) autocorrelation function, and (C) partial autocorrelation function (PACF) of the transformed time series of $\sigma_{\mathrm{p}}$ at $0.10 \mathrm{~m}$ depth. The ACF of the original data indicates that the series is not stationary. The dotted lines mark $2 \times$ standard errors. [Colour figure can be viewed at wileyonlinelibrary.com] 
By using a seasonal trend decomposition (STL method), the large outliers of the remainder (random) return to the irrigation events. Because we already know the timing of the irrigation event, the model can be completed using intervention analysis (irrigation events) and outlier detection (model 10); in this way it becomes invertible and thus reduces its residual variance (Wei, 1989).

Outlier and intervention analysis in the $\sigma_{p}$ time series of the ARIMA model at $0.10 \mathrm{~m}$ depth: Measuring the effect of the irrigation event on $\sigma_{p}$

We applied intervention analysis and automatic outlier detection to the previous ARIMA $(3,1,0)(1,0,0)_{24}$ model in order to improve it and measure the effects of irrigation events on $\sigma_{\mathrm{p}}$ at $0.10 \mathrm{~m}$ depth. With Grubb's test (Equation (6)), 15 outliers were detected (Table I) for the time series of soil water content at $0.10 \mathrm{~m}$ depth.

Including the outlier detection and intervention analysis (effect of irrigation), the observed value of time series of $\sigma_{\mathrm{p}}$ at $0.10 \mathrm{~m}$ depth can be described according to Equation (7) as

Table I. Outlier detection and parameter estimation for time series of soil salinity at $0.10 \mathrm{~m}$

\begin{tabular}{lcc}
\hline Observation time $(\mathrm{h})$ & Type & $\omega$ \\
\hline 103 & AO 0.185 & 7.97 \\
106 & TC 0.125 & 4.55 \\
153 & AO 0.098 & 4.56 \\
494 & TC -0.170 & 6.04 \\
653 & AO 0.300 & 12.20 \\
654 & AO -0.111 & 5.146 \\
770 & TC -0.231 & 7.88 \\
919 & TC -0.111 & 4.18 \\
962 & TC -0.110 & 4.18 \\
1001 & TC -0.118 & 4.32 \\
1029 & TC -0.109 & 4.16 \\
1089 & TC 0.114 & 4.216 \\
1112 & TC -0.286 & 9.32 \\
1113 & TC -0.146 & 5.21 \\
1262 & TC -0.207 & 7.22 \\
\hline
\end{tabular}

$$
\begin{aligned}
X_{t}= & \omega_{r}\left(S_{4.29}^{(t)}+S_{27.20}^{(t)}+S_{32.04}^{(t)}+S_{46.33}^{(t)}\right) \\
& +\sum_{i=1}^{23} \omega_{i} P_{T_{i}}^{(T C)}+\sum_{j=1}^{5} \omega_{j} P_{T_{j}}^{(A O)}+Z_{t}
\end{aligned}
$$

$X_{t}$ is the observed time series; $Z_{t}$ is the time series free of outliers; and $\omega_{r}=-0.759$ represents the permanent change in the mean level after the irrigation event, which characterizes the effectiveness of the irrigation event on the soil salinity. In this study, the flow rate and cut-off time for the four applied irrigations were almost equal; therefore an average coefficient for $\omega_{r}$ was used for estimating the irrigation event's impact. In the $\left(S_{4.29}^{(t)}+S_{27.20}^{(t)}+S_{32.04}^{(t)}+S_{46.33}^{(t)}\right)$ part of the equation, the step indicator is represented for four irrigation times $T_{r}$ (days 4.29, 27.20, 32.04, and 46.33).

The $\omega_{r}\left(S_{4.29}^{(t)}+S_{27.20}^{(t)}+S_{32.04}^{(t)}+S_{46.33}^{(t)}\right)$ part of the equation of a time series for soil salinity $\left(X_{t}\right)$ shows that, at the time of irrigation, the evolution of soil salinity will decrease, and the coefficient $\omega_{r}$ will determine the degree to which it decreases. Moreover, the effects of the 15 detected outliers are represented by the

$$
\sum_{i=1}^{23} \omega_{i} P_{T_{i}}^{(T C)}+\sum_{j=1}^{5} \omega_{j} P_{T_{j}}^{(A O)}
$$

part of the equation.

Applying a Box-Jenkins method to the time series of the soil salinity $\left(\sigma_{\mathrm{p}}\right) Z_{t_{t}}$ from Equation (15), we determine the ARIMA $(3,1,0)(0,1,1)_{24}$. In the usual notation, the model is written as

$$
\begin{aligned}
& \left(1-\varphi_{1} B-\varphi_{2} B^{2}-\varphi_{3} B^{3}\right)(1-B)\left(1-B^{24}\right) Z_{t} \\
& \quad=\left(1+\Theta_{24} B^{24}\right) a_{t}
\end{aligned}
$$

This model (16) is free of outliers and is invertible, with non-significant ACF and PACF of residuals at all lags. Table II provides the comparison of statistical parameters of the two models (14) and (16).

After modelling $\sigma_{\mathrm{p}}$ at a depth of $0.10 \mathrm{~m}$, our next step is to model the $\theta$ and $t$ time series at a depth of $0.10 \mathrm{~m}$ as well as the average soil salinity in the top $0.60 \mathrm{~m}$ of soil. Table III shows the ARIMA models for $\theta$ and $t$ and the average soil salinity in top $0.60 \mathrm{~m}$ of soil; these resulted from following

Table II. Comparison of the two models for soil salinity at $0.10 \mathrm{~m}$ depth in terms of statistical parameters (one based on observed data $X_{t}$ and the second based on outlier-free data $Z_{t}$ )

\begin{tabular}{lcccr}
\hline \multicolumn{1}{c}{ Model } & $\varphi_{1}$ & $\varphi_{2}$ & $\varphi_{3}$ & $\theta_{24}$ \\
\hline Model based on observed data $X_{t}(10)$ & -0.0114 & -0.0684 & & $\sigma^{2}$ \\
Model based on outlier- free data $Z_{t}(12)$ & -0.0467 & -0.0108 & 0.0273 & -0.923 \\
\hline
\end{tabular}


Table III. Models of soil water content $(\theta),(t)$ at $0.10 \mathrm{~m}$ and soil salinity in the upper $0.60 \mathrm{~m}$ of soil

\begin{tabular}{|c|c|c|c|c|c|c|c|c|}
\hline Model & $\varphi_{1}$ & $\varphi_{2}$ & $\varphi_{3}$ & $\varphi_{4}$ & $\varphi_{5}$ & $\Theta_{1}$ & $\theta_{24}$ & $\sigma^{2}$ \\
\hline Soil water & -0.03 & -0.019 & & & & & & $1.06 \times 10^{-5}$ \\
\hline Soil temperature & 1.55 & -0.641 & 0.027 & & & -0.87 & -0.88 & $1.83 \times 10^{-5}$ \\
\hline Soil salinity in the upper $0.60 \mathrm{~m}$ of soil & 0.07 & 0.158 & 0.11 & 0.05 & -0.04 & -0.54 & & $1.56 \times 10^{-5}$ \\
\hline
\end{tabular}

the same steps applied to model $\sigma_{\mathrm{p}}$ at a depth of $0.10 \mathrm{~m}$. The effects of the irrigation events on the time series of $\theta$ and $t$ at $0.10 \mathrm{~m}$ were 0.0843 and 0.288 , respectively.

After having identified all the models and estimating the parameters, diagnostic checks are then applied to the fitted model to verify whether the model is adequate.

\section{Transfer function method}

Looking at the cross-correlation between the pre-whitened, primary time series (soil water and temperature at a depth of $0.10 \mathrm{~m})$ and target soil salinity $(0.10 \mathrm{~m}$ depth and the average), we see an effect from the primary series on the target series, but not vice versa. Figure 3 indicates that the current values of soil water, content and temperature at $0.10 \mathrm{~m}$ have a significant effect on the current soil salinity values at a depth of $0.10 \mathrm{~m}$ and on the average soil salinity in the top $0.60 \mathrm{~m}$ of soil.

Models were identified for predicting soil salinity based on soil water content and soil temperature at a depth of $0.10 \mathrm{~m}$ (Table IV). The coefficients of $X_{t}$ in Table IV's equations indicate that the current values of soil water content and soil temperature at $0.10 \mathrm{~m}$ have effects,
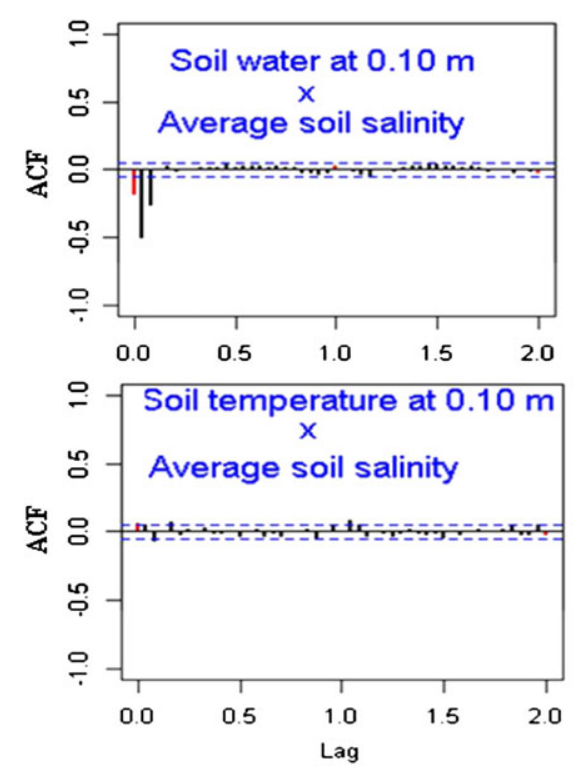

respectively, of -7.82 and -0.050 on the current values of soil salinity at a depth of $0.10 \mathrm{~m}$. Furthermore, the current values of soil water content and soil temperature at $0.10 \mathrm{~m}$ depth have effects, respectively, of -1.68 and -0.004 on the current values of the average soil salinity in the soil's top $0.60 \mathrm{~m}$.

\section{Forecasting}

Figure 4 shows the calibration of the model as well as its predictions of average soil salinity and soil salinity at $0.10 \mathrm{~m}$ depth. The first 659 observations of each time series were used to define the model. The output of the calibrated model corresponded very well to the values before 659 for each depth. The predicted and observed values after the 659 observations agreed reasonably. There were sometimes large relative differences between the values that were predicted and those that were observed. However, the absolute difference between prediction and measurement never exceeded $0.27 \mathrm{dS} \mathrm{m}^{-1}$.

Figure 5 provides an example of using the transfer function model presented in Table IV to predict soil salinity over 2 days at a depth of $0.10 \mathrm{~m}$ and in the top $0.60 \mathrm{~m}$ of soil. Soil
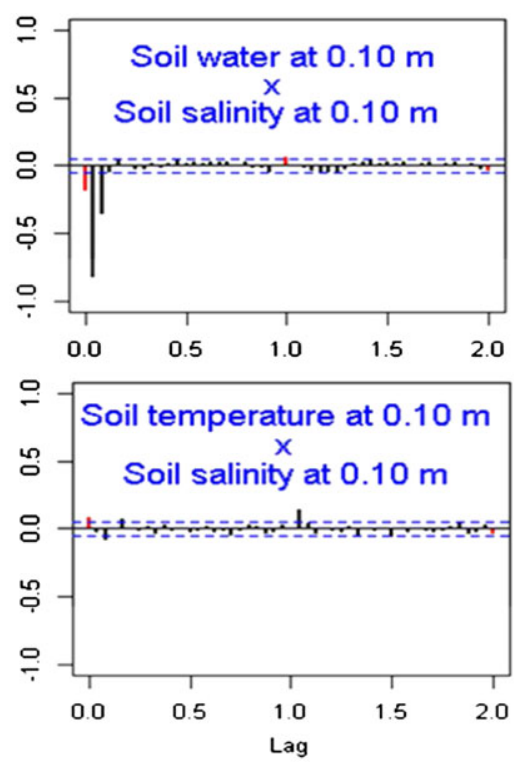

Figure 3. Cross-correlation function for soil water content and soil temperature hourly time series at $0.10 \mathrm{~m}$ and soil salinity at $0.10 \mathrm{~m}$ depth. Cross-correlation function for soil water content and soil temperature $0.10 \mathrm{~m}$ and soil salinity in the top $0.60 \mathrm{~m}$ of soil profile, respectively. Dashed lines indicate $95 \%$ confidence limits. [Colour figure can be viewed at wileyonlinelibrary.com] 
Table IV. Time series transfer function model for soil salinity at $0.10 \mathrm{~m}$ depth and in the top of $0.60 \mathrm{~m}$ of the soil profile

Soil water content $X_{1}, t$, soil temperature $X_{2, t}$ at $0.10 \mathrm{~m}$ and soil salinity $Y_{t}$ at $0.10 \mathrm{~m}$ :

$$
Y_{t}=\frac{\left(-7.8242+1.4053 B-0.2606 B^{2}+0.7234 B^{3}\right) X_{1, t}+(-0.0508+0.0153 B) X_{2, t}+a_{t}}{(1-B)\left(1+0.680 B^{24}\right)\left(1+0.1597 B+0.1266 B^{2}+0.0502 B^{3}\right)}
$$

Soil water content $X_{1}$, , soil temperature $X_{2},{ }_{t}$ at $0.10 \mathrm{~m}$ and average soil salinity $Y_{t}$

$Y_{t}=\frac{\left(-1.6855-0.0548 B+0.4975 B^{2}+0.0717 B^{3}\right) X_{1, t}+(0.004-0.0111) X_{2, t}+a_{t}}{(1-B)\left(1-0.0358 B^{24}\right)\left(1-0.0627+0.0209 B^{2}-0.1754 B^{3}\right)}$

$$
a_{t} \sim N\left(0,2.684 \times 10^{-5}\right)
$$

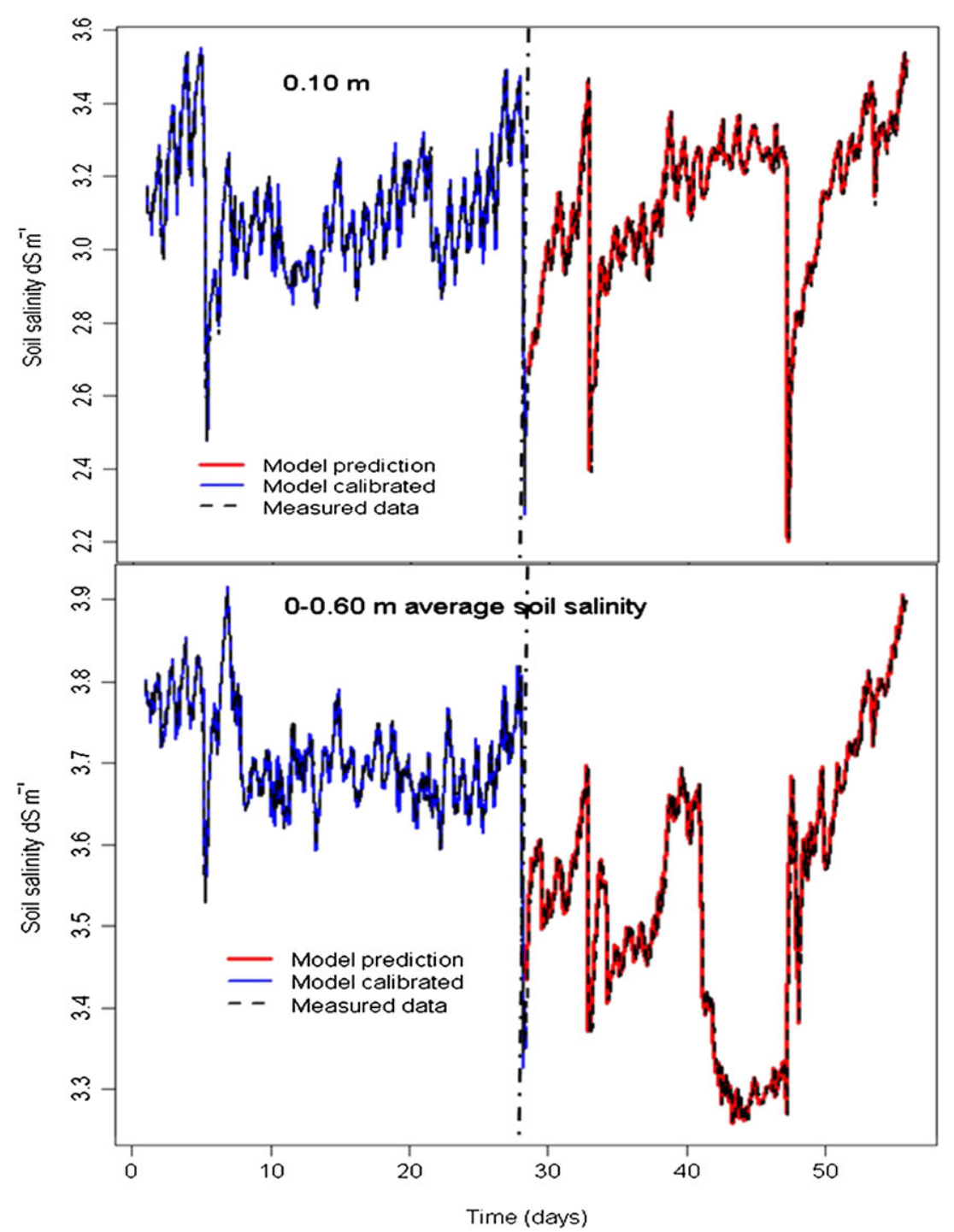

Figure 4. Measured and predicted soil salinity versus time at $0.10 \mathrm{~m}$ depth and in the top $0.60 \mathrm{~m}$ of soil profile. Prediction was based on the identified transfer function models for each one. The curve before the vertical dashed line refers to model calibration and after the vertical dashed line to model prediction. [Colour figure can be viewed at wileyonlinelibrary.com] 

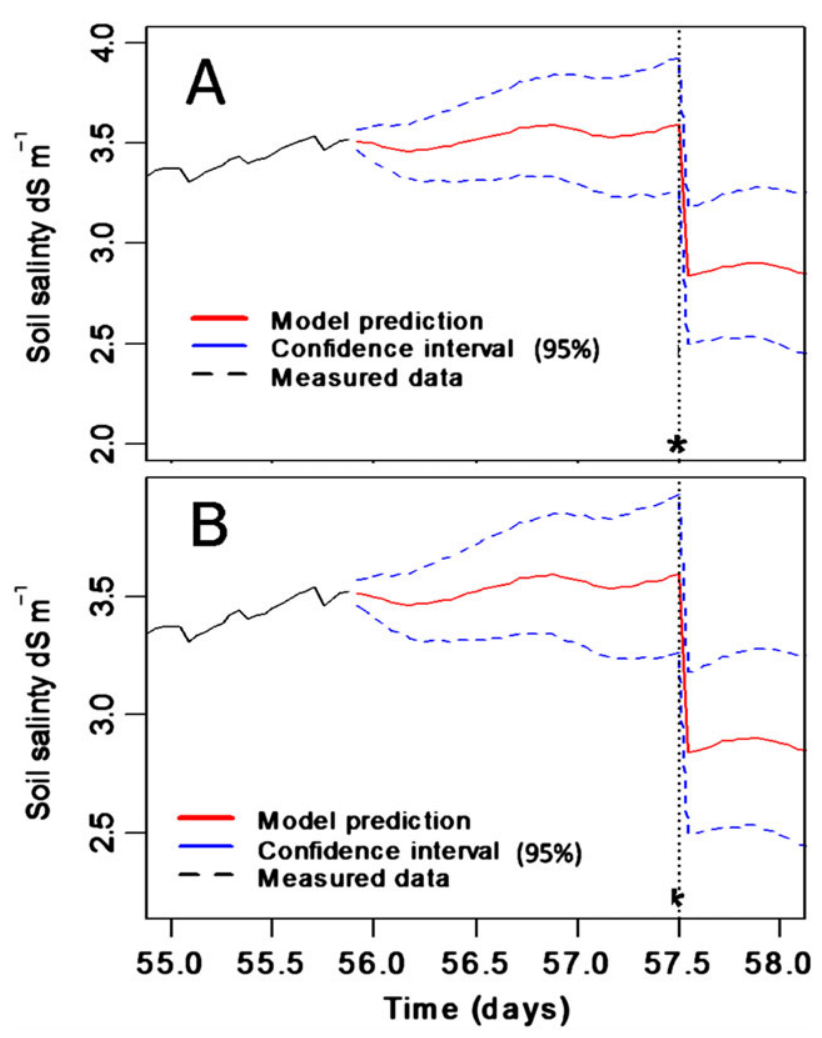

Figure 5. Prediction models for soil salinity at $0.10 \mathrm{~m}$ depth (A) and average soil salinity in the top $0.60 \mathrm{~m}$ of soil profile (B). Prediction was based on the indentified transfer function. We have observed data for 55 days, the model predicts the 56th and 57th days, taking into account the effect of next irrigation if the farmer chose to irrigate on 57.5 th day $(*$ is the irrigation time at 57.5th day). [Colour figure can be viewed at wileyonlinelibrary.com]

salinity was observed at 55 days, and the prediction is for the 56th and 57th days $(48 \mathrm{~h})$. It includes the effect of the next irrigation if the farmer chooses to irrigate after $36 \mathrm{~h}$. The figure shows how the irrigation event at day 57.5 affects soil salinity evolution; this effect is determined by the $\omega_{r}$ from Equation (15).

However, in this study, the 48 -h predicted value decreases, while the lead time increases but still remains within the confidence interval (95\%).

\section{CONCLUSION}

Modelling and predicting salinity in soils under variable interval irrigation are not valid if changes in irrigation frequency are not taken into account. We studied the time series under such a regime, specifically for soil salinity $\left(\sigma_{\mathrm{p}}\right)$, soil water content $(\theta)$ and soil temperature $(t)$-all of them at a depth of $0.10 \mathrm{~m}$ in a lettuce field of silty loam soil. Each time series was transformed into a stationary series; then, we constructed ARIMA models for studying each time series and for making predictions. The ARIMA model with an underlying normality assumption could not properly predict soil salinity. Therefore, the model was completed by means of intervention analysis (with the interventions being irrigation events) as well as outlier detection (in order to identify unusual observations). We then used transfer function models (multiple-input/one-output) to predict $\sigma_{\mathrm{p}}$ at our depths of interest $(0.10 \mathrm{~m}$ and the average $\sigma_{\mathrm{p}}$ in the upper $0.60 \mathrm{~m}$ of soil); this was done using the measured water $\theta$ and $t$ at $0.10 \mathrm{~m}$ depth and produced rational predictions. The subsequent irrigation and decrease in $\sigma_{\mathrm{p}}$ after that irrigation event were correctly estimated. Since the irrigation doses for the four irrigation events in this study were almost the same, we used an average mean level $\left(\omega_{r}=0.087\right)$ to show an irrigation event's effectiveness on the soil salinity time series. In cases involving variable doses of irrigation, our suggestion is to study the effect of each irrigation event and to then include each effect separately in the model. Moreover, the time series analysis in our study applies mathematical models to one soil profile at different depths in order to find certain relationships among the observed variables $\left(\sigma_{\mathrm{p}}, \theta\right.$ and $\left.t\right)$. However, in order to validate the model we used for the whole area of study, we recommend using additional measurements of $\sigma_{\mathrm{p}}, \theta$ and $t$ from different soil profiles to take into account the spatial variability of the study area. Lastly, future studies should look toward further consideration of how these sensors and their data can be positioned in a way that makes them more accessible for practical use. At present, capacitance sensors of this type are available on the commercial market; however, they are limited almost exclusively to use in scientific experiments. This can be attributed to the process involved, whereby the technician is required to travel to the field with a computer in order to transfer the sensor data from the datalogger to an Excel spreadsheet. From this, mathematics is then applied for studying the relationship between the variables. As an alternative, an electronic unit could be designed to be included in the sensor datalogger, which may result from telecommunication technicians incorporating our stochastic models. This would allow for the provision of a visual indication of the electrical conductivity of the soil solution. Our study finds that, with the proper programming, this low-cost sensor could be expanded in a way that provides further beneficial capabilities, such as allowing a normal farmer the opportunity to ascertain salt levels in the root zone.

\section{ACKNOWLEDGMENTS}

This work was funded by Parc Agrari Del Baix Llobregat (Barcelona). Special thanks go to the Alexander von Humboldt Foundation for financing the time to write this paper. 


\section{NOTATION}

$\sigma_{b}$
$T$
$\Theta$
$\sigma_{p}$

ARIMA

$\varepsilon_{p}$

$\varepsilon_{b}$

$\varepsilon_{\sigma b}=0$

$P$

$Q$

$P$

$Q$

$D$

D

$S$

AR

$\varphi_{j}$

$a_{t}$

$B$

MA

$\theta_{q}$

$\theta_{q}$

$\varphi_{p}(B)$

$\theta_{q}(B)$

$\Phi_{P}\left(B^{S}\right)$

$\Theta_{Q}\left(B^{s}\right)$

$\mathrm{ACF}$

PACF

Z

M

V

SD

AO

TC

LS

$\omega_{r} \omega \mathrm{r}$

$S_{T_{r}}^{(L S)}$

$\mathrm{STr}(\mathrm{LS})$

$\omega \mathrm{i}$

$P_{T_{i}}^{(T C)} \quad$ Pulse indicators taken at unusual observation

PTi(Tc)

$P_{T_{j}}^{(A O)} \quad$ Pulse indicators taken at unusual observation

PTj(Ao)

$\delta$

Bulk electrical conductivity ( $\left.\mathrm{dS} \mathrm{m}^{-1}\right)$

Soil temperature

Soil water content

Electrical conductivity of the pore water (dS $\mathrm{m}^{-1}$ )

Seasonal autoregressive integrated moving average

Real portion of the soil pore water's dielectric permittivity (unitless)

Real portion of the bulk soil's dielectric permittivity (unitless)

Offset of $\sigma_{p} \sim \varepsilon_{b}$ relationship

Regular autoregressive factor

Regular moving average order

Seasonal autoregressive order

Seasonal moving average order

Orders of differencing for the regular part

Orders of differencing for the seasonal part

Subindex represents the seasonal period

Part of the autoregressive process

Denotes the $j$ th AR parameter

Gaussian white-noise error

Backshift operator in which $B^{p} X_{t}=X_{t}-p$.

Moving average process

$q$ th MA parameter

$q$ th MA parameter

Regular autoregressive factor

Regular moving average factor

Seasonal autoregressive factor

Seasonal moving average factor

Autocorrelation function

Partial autocorrelation function

Test statistic

Mean of the value

Value being tested

Standard deviation of the values

Additive outliers

Temporary changes

Level shift

Permanent change in the mean level following

the irrigation event

Step indicator at the time of irrigation $T_{r}$

Transitory change in the mean level following any unusual observations

times $T_{i}$

times $T_{j}$

Dampening factor with the default value of

0.7

STL

$A(B) / C(B)$

$Z_{t}$

Seasonal-trend decomposition

System's designated transfer function

Time series free of outliers

\section{REFERENCES}

Aljoumani B, Sànchez-Espigares JA, Cañameras N, Josa R, Monserrat J. 2012. Time series outlier and intervention analysis: irrigation management influences on soil water content in silty loam soil. Agricultural Water Management 111: 105-114. https://doi.org/10.1016/j.agwat. 2012.05.008.

Aljoumani B, Sànchez-Espigares JA, Cañameras N, Josa R. 2014. An advanced process to evaluate the linear dielectric constant-bulk electrical conductivity model using capacitance sensor in field conditions. Hydrological Sciences Journal 60. https://doi.org/10.1080/02626667. 2014.932053.

Beven K, Germann P. 1982. Macropores and water flow in soils. Water Resources Research 18(5): 1311-1325. https://doi.org/10.1029/ WR018i005p 01311.

Box GEP, Jenkins GM, Reinsel GC. 1994. Time Series Analysis: Forecasting and Control. 3rd edn.Englewood Cliffs, NJ, USA: Prentice Hall.

Chaloupka M. 2001. Historical trends, seasonality and spatial synchrony in green sea turtle egg production. Biological Conservation 101(3): 263-279. https://doi.org/10.1016/S0006-3207(00)00199-3.

Chen C, Liu L. 1993. Joint estimation of model parameters and outlier effects in time series. Journal of the American Statistical Association 88(421): 284-297. https://doi.org/10.2307/2290724.

Cleveland RB, Cleveland WS, McRae JE, Terpenning I. 1990. STL: a seasonal trend decomposition procedure based on loess. Journal of Official Statistics 6(1): 3-73.

Cryer JD, Chan KS. 2008. Time Series Analysis with Applications in R, 2nd ed. Springer: New York. https://doi.org/10.1007/978-0-38775959-3.

Fortin JG, Anctil F, Parent L, Bolinder MA. 2010. A neural network experiment on the site-specific simulation of potato tuber growth in eastern Canada. Computers and Electronics in Agriculture 73(2): 126-132. https://doi.org/10.1016/j.compag.2010.05.011.

Genuchten Van MT. 1991. Recent progress in modelling water flow and chemical transport in the unsaturated zone. In Kienitz G, Milly PCD, Van Genuchten MT, Rosbjerg D, Shuttleworth WJ (eds). Hydrological interactions between atmosphere, soil and vegetation. Proceedings of an international symposium held during the XXth General Assembly of the International Union of Geodesy and Geophysics at Vienna, 11-24 August 1991. IAHS. Publ. No 204: Wallingford; S. 169-183.

Green TR, Salas JD, Martinez A, Erskine RH. 2007. Relating crop yield to topographic attributes using spatial analysis neural networks and regression. Geoderma 139(1-2): 23-37. https://doi.org/10.1016/j.geoderma. 2006.12.004.

Grubbs F. 1969. Procedures for detecting outlying observations in samples. Technometrics 11(1): 1-21. https://doi.org/10.1080/00401706.1969. 10490657.

Hafen R, Anderson D, Cleveland W, Maciejewski R, Ebert D, Abusalah A, Yakout M, Ouzzani M, Grannis S. 2009. Syndromic surveillance: STL for modeling, visualizing, and monitoring disease counts. BMC Medical Information and Decision Making 9(21). https://doi.org/10.1186/14726947-9-21.

Hilhorst MA. 2000. A pore water conductivity sensor. Soil Science Society of America Journal 64(6): 1922-1925. https://doi.org/10.2136/ sssaj2000.6461922x.

Hoff JC. 1983. A Practical Guide to Box-Jenkins Forecasting. Lifetime Learning Publications: London. 
Huang Y, Lan Y, Thomson SJ, Fang A, Hoffmann WC, Lacey RE. 2010. Development of soft computing and applications in agricultural and biological engineering. Computers and Electronics in Agriculture 71(2): 107-127. https://doi.org/10.1016/j.compag.2010.01.001.

Khazaei J, Naghavi MR, Jahansouz MR, Salimi-Khorshidi G. 2008. Yield estimation and clustering of chickpea genotypes using soft computing techniques. Agronomy Journal 100(4): 1077-1087. https://doi.org/ 10.2134/agronj2006.0244.

Malicki MA, Walczak RT, Koch S, Flühler H. 1994. Determining soil salinity from simultaneous readings of its electrical conductivity and permittivity using TDR. In Proceedings of the Symposium on Time Domain Reflectometry in Environmental, Infrastructure, and Mining Applications, Evanston, USA, 7-9 September. US Bureau of Mines, Special Publication SP 19-94, NTIS PB95-105789; 328-336.

McCleary R, Hay RA. 1980. Applied Time Series Analysis for the Social Sciences. Sage Publications Inc.: Thousand Oaks, Calif.

McDowall D, McCleary R, Meidinger EE, Hay RA. 1980. Interrupted Time Series Analysis. Sage Publications: Beverly Hills, Calif.

McKenzie RC, Chomistek W, Clark NF. 1989. Conversion of electromagnetic inductance readings to saturated paste extract values in soils for different temperature, texture, and moisture conditions. Canadian Journal of Soil Science 69(1): 25-32. https://doi.org/ 10.4141/cjss89-003.

Mishra AK, Desai VR. 2005. Drought forecasting using stochastic models. Stochastic Environmental Research and Risk Assessment 19(5): 326-339. https://doi.org/10.1007/s00477-005-0238-4.

Mualem Y, Friedman SP. 1991. Theoretical prediction of electrical conductivity in saturated and unsaturated soil. Water Resources Research 27(10): 2771-2777. https://doi.org/10.1029/91WR01095.

Munns R. 2002. Comparative physiology of salt and water stress. Plant, Cell and Environment 25(2): 239-250. https://doi.org/10.1046/j.00168025.2001.00808.x.

Pankratz A. 1983. Forecasting with Univariate Box-Jenkins Models: Concepts and Cases. John Wiley \& Sons: New York.

Park SJ, Hwang CS, Vlek PLG. 2005. Comparison of adaptive techniques to predict crop yield response under varying soil and land management conditions. Agricultural Systems 85(1): 59-81. https://doi.org/10.1016/ j.agsy.2004.06.021.

Quinn TJ II. 1985. Catch-per-unit-effort: a statistical model for Pacific halibut (Hippoglossus stenolepis). Canadian Journal of Fisheries and Aquatic Sciences 42(8): 1423-1429. https://doi.org/10.1139/f85-178.
R Development Core Team. 2012. R: A Language and Environment for Statistical Computing. R Foundation for Statistical Computing: Vienna, Austria; ISBN:3-900051-07-0 URL http://www.r-project.org/.

Rhoades JD, Shouse PJ, Alves WJ, Manteghi NA, Lesch.SM. 1990. Determining soil salinity from electrical conductivity using different models and estimates. Soil Science Society of America Journal 54(1): 45-54. https://doi.org/10.2136/sssaj1990.03615995005400010007x.

Sarangi A, Singh M, Bhattacharya AK, Singh AK. 2006. Subsurface drainage performance study using SALTMOD and ANN models. Agricultural Water Management 84: 240-248. https://doi.org/10.1016/j. agwat.2006.02.009.

Shumway RH, Stoffer DS. 2006. Time Series Analysis and its Applications. With R Examples. Springer: New York. https://doi.org/10.1007/0-38736276-2.

Slavich PG, Peterson GH. 1990. Estimating the electrical conductivity of saturated paste extracts from 1: 5 soil-water suspensions and texture. Australian Journal of Soil Research 31(1): 73-81. https://doi.org/ 10.1071/SR9930073.

Soebiyanto RP, Adimi F, Kiang RK. 2010. Modeling and predicting seasonal influenza transmission in warm regions using climatological parameters. PLoS One 5(3): e9450. https://doi.org/10.1371/journal. pone.0009450.

Vandaele W. 1983. Applied Time Series and Box-Jenkins Models. Academic Press: New York.

Wei WWS. 1989. Time Series Analysis: Univariate and Multivariate Methods. Pearson Addison-Wesley: New York.

White RE. 1985. The influence of macropores on the transport of dissolved and suspended matter through soil. Advances in Soil Science 3: 95-120.

Wu L, Jury WA, Chang AC, Allmaras RR. 1997. Time series analysis of field-measured water content of a sandy soil. Soil Science Society of America Journal 61(3): 736-742. https://doi.org/10.2136/sssaj1997. $03615995006100030005 x$.

Zhang JQ, Zhang LX, Zhang MH, Watson C. 2009. Prediction of soybean growth and development using artificial neural network and statistical models. Acta Agronomica Sinica 35(2): 341-347. https://doi.org/ 10.1016/S1875-2780(08)60064-4.

Zou P, Yang J, Fu J, Liu G, Li D. 2010. Artificial neural network and time series models for predicting soil salts and water content. Agricultural Water Management 97(12): 2009-2019. https://doi.org/10.1016/j.agwat. 2010.02.011. 